This document is the accepted manuscript version of the following article:

Bekar, İ., Tavşanoğlu, Ç., Pezzatti, G. B., Vacik, H., Pausas, J. G., Bugmann, H., \& Petter, G. (2020). Cross-regional modelling of fire occurrence in the Alps and the Mediterranean Basin.

International Journal of Wildland Fire, 29(8), 712-722. https://doi.org/10.1071/WF19158

\title{
Cross-regional modelling of fire occurrence in the Alps and the Mediterranean Basin
}

\author{
Ismail Bekar (D) A,F, Çağatay Tavsanoğlu ${ }^{\mathrm{B}}, \mathrm{G}$. Boris Pezzatti ${ }^{\mathrm{C}}$, Harald Vacik $^{\mathrm{D}}$, \\ Juli G. Pausas ${ }^{\mathrm{E}}$, Harald Bugmann ${ }^{\mathrm{A}}$ and Gunnar Petter ${ }^{\mathrm{A}}$ \\ ${ }^{A}$ Forest Ecology, Institute of Terrestrial Ecosystems, Swiss Federal Institute of Technology, ETH \\ Zurich, Universitätstrasse 16, 8092 Zü rich, Switzerland. \\ ${ }^{B}$ Division of Ecology, Department of Biology, Hacettepe University, Beytepe 06800, Ankara, \\ Turkey. \\ C Insubric Ecosystems Research Group, Swiss Federal Research Institute for forest, snow and \\ landscape research WSL, Campus Cadenazzo, A Ramel 18, 6593 Cadenazzo, Switzerland. \\ DInstitute of Silviculture, University of Natural Resourcesand Life Sciences(BOKU), Peter Jordan \\ Str. 82, 1190 Vienna, Austria. \\ ${ }^{\mathrm{E}}$ Centro de Investigaciones sobre Desertificación, Consejo Superior de Investigaciones Científicas \\ (CIDE-CSIC), 46113 Valencia, Spain. \\ FCorresponding author. Email: ibekar@ethz.ch
}

\begin{abstract}
In recent decades, changes in fire activity have been observed in Europe. Fires can have large consequences for the provisioning of ecosystem services and for human well-being. Therefore, understanding the drivers of fire occurrence and improving the predictive capability of fire occurrence models is of utmost importance. So far, most studies have focused on individual regions with rather low spatial resolution, and have lacked the ability to apply the models in different regions. Here, a species distribution modelling approach (Maxent) was used to model fire occurrence in four regions across the Mediterranean Basin and the Alps using several environmental variables at two spatial resolutions. Additionally, a cross-regional model was developed and spatial transferability tested. Most models showed good performance, with fine resolution models always featuring somewhat higher performance than coarse resolution models. When transferred across regions, the performance of regional models was good only under similar environmental conditions. The cross-regional model showed a higher performance than the regional models in the transfer tests. The results suggest that a cross-regional approach is most robust when aiming to use fire occurrence models at the regional scale but beyond current environmental conditions, for example in scenario analyses of the impacts of climate change.
\end{abstract}

\section{Introduction}

Wildfires play an important role in many terrestrial ecosystems and have a variety of ecological, evolutionary and economic effects (Bond et al. 2005; Pausas and Keeley 2009). In recent decades, changing trends in fire activity have been observed in many parts of the world (Schelhaas et al. 2003; Westerling et al. 2006; Pausas and Fernández-Muñoz 2012; Turco et al. 2016), with further changes likely (Schumacher and Bugmann 2006; Jolly et al. 2015). The increasing fingerprint of human activity on landscape properties and anthropogenic climate change are the main reasons for these trends (Dimitrakopoulos et al. 2011; Seidl et al. 2011). The disruption of natural fire regimes may have far-reaching consequences for ecosystem functions and services, and ultimately for human well-being (Pausas and Keeley 2019). A better understanding of the spatial and temporal distribution of wildfire occurrence and a better predictive capability are therefore of utmost importance.

In Europe, fire regimes differ substantially across regions. The Mediterranean Basin is most fire-prone, accounting for up to $90 \%$ of the forest area burnt in Europe (Seidl et al. 2011). Fire occurrence in this area has recently increased significantly owing to climatic (Dimitrakopoulos et al. 2011; Seidl et al. 2011) and land-use changes (Pausas and Fernández-Muñoz 2012). Ongoing climate change may increase fire risk also in parts of the continent where it currently has only modest effects, such as Central or Northern Europe (Schumacher and Bugmann 2006; Müller et al. 2015). Additionally, anthropogenic influences such as land abandonment, grazing or changes of forest management have already led to changes in fire activity in Europe (Pausas and Keeley 2014). An analysis of both climatic 
and anthropogenic factors is therefore crucial to better understand potential changes of fire occurrence.

Several modelling approaches have been used to simulate the spatial distribution of fire occurrence, for example Generalised Linear Models (Camp and Krawchuk 2017), Maximum Entropy Models (Maxent; Renard et al. 2012) or Zero-Inflated Regression Models (Bekar and Tavsanoğlu 2017). These models are methodologically and conceptually related to species distribution models (SDMs; Guisan and Zimmermann 2000; Elith and Leathwick 2009). Although the distributions of species and wildfires seem to have little in common at first sight, from a statistical modelling point of view both describe a certain probability of occurrence of an entity (fire, species) in space and time, being determined by a range of factors. Among the many SDM methods, Maxent models have shown comparably high prediction accuracies (Elith et al. 2006), perform well even with small sample sizes (Guisan et al. 2007b) and have already been used for modelling fire risk (Parisien and Moritz 2009; Parisien et al. 2012; Renard et al. 2012; Arpaci et al. 2014; De Angelis et al. 2015). Apart from assessing prediction accuracy, these models allow for evaluating the relative importance of the different factors potentially influencing fire occurrence (Arpaci et al. 2014).

The importance of climatic, ecological and anthropogenic factors influencing fire occurrence can differ substantially among different regions in Europe (Conedera et al. 2018). For example, the spatial variability of fire occurrence in the western part of the Mediterranean Basin was strongly influenced by anthropogenic factors (Spain; Chergui et al. 2017), whereas natural factors were the main driver in the eastern part of the basin (Turkey; Bekar and Tavsanoğlu 2017). Our knowledge of the small-scale drivers of fire occurrence has significantly increased in recent decades (Moreira et al. 2001; Vilar et al. 2010); however, small-scale studies on the importance of factors for fire occurrence are often not directly comparable and thus do not provide adequate information to assess the relative importance of factors at continental scales. Large-scale studies on fire occurrence would therefore be valuable, but previous studies have used coarse resolutions that are not sufficient to capture small-scale drivers (Koutsias et al. 2005, 2010).

The spatial resolution of SDMs was found to have a considerable effect on model results (Guisan et al. 2007a; Gottschalk et al. 2011). However, results from previous studies are not consistent. While increasing spatial resolution tends to make small-scale features more distinguishable, it can also lead to accuracy errors if the spatial accuracy of the presence data is low (Gottschalk et al. 2011). Specifically, Cardille et al. (2001) found that an increased resolution in fire occurrence models resulted in a decrease in their performance, while the relative importance of the predictor variables was unaffected. In contrast, other studies found a positive effect of increasing spatial resolution on model performance for various target organisms (Guisan et al. 2007a, 2007b; Gottschalk et al. 2011; Ross et al. 2015). Moreover, Guisan et al. (2007b) suggested that the effect of spatial resolution on environmental variables is likely to be regionally variable. Thus, further research on the influence of spatial resolution is required, particularly in the fire modelling context.

Spatial transferability of statistical models is an important feature, one that may allow us to reduce research cost and save time by using models in areas where data availability is insufficient or lacking entirely. However, transferability requires models that are capable of predicting phenomena beyond the range of data for which they were developed. Thus, a better understanding of the transferability of fire occurrence models in time or across space is required before applying them under novel conditions. Weibel (2009) tested the generality of fire occurrence models in Switzerland, showing that model transfer was possible in time but not in space. Alternatively, Parisien and Moritz (2009) used a multi-spatial scale approach in the USA and found that model transfers performed better from a larger region to an embedded sub-region. However, no attempt has been made so far to test these findings for fire occurrence models in a large-scale study in Europe.

In the present study, the first goal was to investigate the importance of predictors and the spatial resolution for fire occurrence (regardless of fire cause) across several regions in the Alps and the Mediterranean Basin. We developed regional Maxent models for four regions in different countries (Switzerland, Austria, Turkey and Spain), as well as one cross-regional model, and assessed the region-specific relative importance of the predictors of wildfire occurrence and the effect of two spatial resolutions (grid cell size: $1 \mathrm{~km}$ and $100 \mathrm{~m}$ ) on model performance. The second goal was to investigate the transferability of the models in space. We used multiple indicators of model performance to determine how these models perform when being transferred across regions and relative to the cross-regional model.

\section{Methods}

\section{Study areas and fire data}

We chose four study regions across the Alps (Carinthia in Southern Austria, hereafter Austria; Southern Alps of Switzerland, hereafter, Switzerland; Fig. 1) and the Mediterranean Basin (Valencia in Eastern Spain, hereafter Spain; South-western Turkey hereafter, Turkey; Fig. 1). They cover a broad spectrum of ecological, climatic and topographic conditions and represent distinctly different fire regimes. The selection of the regions was partly driven by data availability and the existence of fire ecology studies (Pausas 2004; Zumbrunnen 2010; Grima 2011; Bekar 2016). For these countries, fire occurrence data (i.e. data specifying the georeferenced location and time of wildfires) were available. More details on the four regions and fire data are provided in Table 1 and Figs S1-4, Supplementary Material.

\section{Environmental variables}

We used 19 bioclimatic variables from the WorldClim database (version 2.0) with a spatial resolution of 30 arc seconds ( 1 $\mathrm{km}^{2}$ ) for the years 1970-2000 (Fick and Hijmans 2017; Table 2) as climate input data. Anthropogenic factors were represented by road line density $\left(\mathrm{m} \mathrm{km}^{-2}\right)$, the fraction of area occupied by human settlements (\%) and categorical land cover data (Table 2). Road line density was calculated based on road network data using the Line Density tool in ArcGIS (v10.4.1, ESRI, Redlands, CA; Haklay and Weber 2008). Tree cover density and forest type data were used to represent vegetationrelated variables; aspect and slope were used to represent topography (Table 2). 


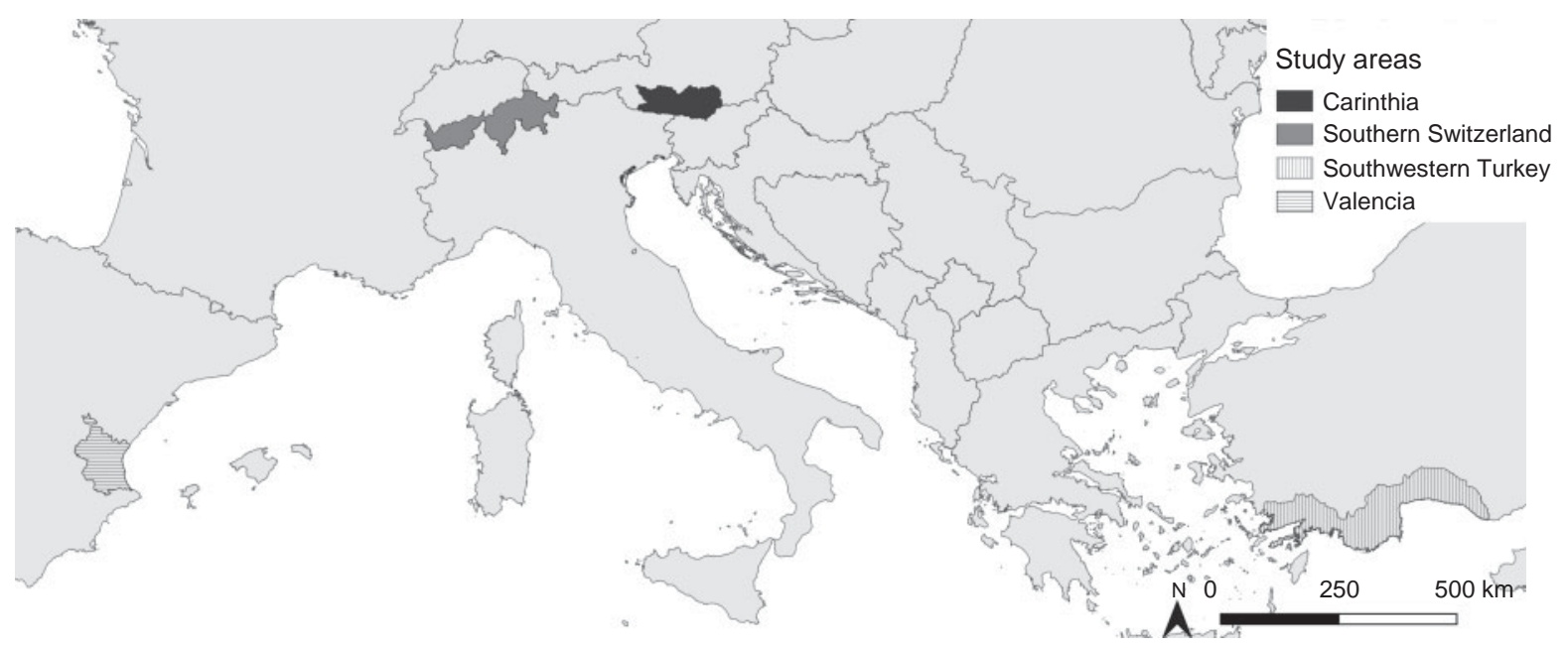

Fig. 1. Location of the study regions in Spain, Switzerland, Austria and Turkey.

Table 1. Total area, number of fires, number of cells with at least one fire and fire causes in the study areas

A lower number of cells with fire than the total number of fires indicates more than one fire occurrence in a cell. a, Anthropogenic; n, natural; u, unknown

\begin{tabular}{|c|c|c|c|c|c|c|c|c|}
\hline & \multirow[t]{2}{*}{ Period } & \multirow[t]{2}{*}{ Area $\left(\mathrm{km}^{2}\right)$} & \multirow[t]{2}{*}{ Number of fires } & \multicolumn{3}{|c|}{ Fire causes (\%) } & \multirow{2}{*}{$\begin{array}{l}\text { Number of cells } \\
\text { with fire (fine } \\
\text { resolution) }\end{array}$} & \multirow{2}{*}{$\begin{array}{c}\text { Number of cells } \\
\text { with fire (coarse } \\
\text { resolution) }\end{array}$} \\
\hline & & & & a & $\mathrm{n}$ & $\mathrm{u}$ & & \\
\hline Switzerland & $2000-16$ & 9536 & 831 & 57 & 21 & 10 & 806 & 709 \\
\hline Austria & $2000-17$ & 15141 & 491 & 80 & 20 & 0 & 485 & 456 \\
\hline Spain & $2001-14$ & 23255 & 2688 & 76 & 21 & 3 & 2514 & 1844 \\
\hline Turkey & 2013-17 & 32831 & 2512 & 28 & 20 & 52 & 2398 & 2061 \\
\hline
\end{tabular}

Table 2. Characteristics of the variables used as predictors in the Maxent model (for a full list of variables, see Table S1 in Supplementary Material)

\begin{tabular}{|c|c|c|c|c|}
\hline Variable & Category & Description & Resolution & Year \\
\hline Bioclimatic variables $^{\mathrm{A}}$ & Temperature, Precipitation & 19 variables & $1 \mathrm{~km}^{2}$ & $1970-2000$ \\
\hline Road network $^{\mathrm{B}}$ & Anthropogenic & Road line density $\left(\mathrm{m} \mathrm{km}^{-2}\right)$ & Vector & 2018 \\
\hline Human settlement $^{\mathrm{C}}$ & Anthropogenic & Percentage of built-up area (\%) & $100 \mathrm{~m}^{2}$ & 2012 \\
\hline Land cover ${ }^{\mathrm{C}}$ & Anthropogenic & Categorical land cover data & $100 \mathrm{~m}^{2}$ & 2012 \\
\hline Tree cover density ${ }^{\mathrm{C}}$ & Forest & Tree cover density (\%) & $100 \mathrm{~m}^{2}$ & 2012 \\
\hline Forest type $\mathrm{C}^{\mathrm{C}}$ & Forest & Categorical forest type data (broadleaved or coniferous) & $100 \mathrm{~m}^{2}$ & 2012 \\
\hline Aspect $^{\mathrm{C}}$ & Topography & Direction that a slope faces $(0-3608)$ & $25 \mathrm{~m}^{2}$ & \\
\hline Slope ${ }^{\mathrm{C}}$ & Topography & (8) & $25 \mathrm{~m}^{2}$ & \\
\hline
\end{tabular}

${ }^{A}$ WorldClim (http://www.worldclim.org/current, verified March 2020)

${ }^{\mathrm{B}}$ OpenStreetMap (https://www.openstreetmap.org/, verified March 2020)

${ }^{\mathrm{C}}$ Copernicus (https://land.copernicus.eu/, verified March 2020)

For the coarse-resolution analyses, all variables except climate were resampled to 1-km resolution using the Resample tool in ArcGIS. For the fine-resolution analysis, climate and topographical variables were resampled to $100 \mathrm{~m}$. We used a bilinear resampling rule for continuous data, which calculates the new value of the cell based on a weighted distance average of the four nearest cell centres, whereas for categorical variables (land cover, forest type), the majority rule was used, which determines the new cell value based on the most common values across the neighbouring cells.

\section{Spatial fire distribution model}

We modelled fire occurrence using Maxent, a machine-learning method based on maximum entropy that was initially developed mainly for modelling species distributions from presence-only records (Phillips et al. 2006). By default, Maxent provides a few 
evaluation metrics, one of them being the Area Under the Curve (AUC) of the Receiver-Operating Characteristic (ROC). An AUC graph shows sensitivity (truepositives) against 1-specificity (true negatives). It is worth noting that for Maxent the maximum achievable AUC is , 1 because it compares presence points with background points instead of absence points (Parisien et al. 2012). For all simulations, we used 10 replicates with a $50: 50$ split of training $v$. test data. A subsampling method was used to create randomly selected test and training data. We used the Maxent algorithm as implemented in the dismo package of the statistical software $R$ (Hijmans et al. 2017; R Core Team 2018).

\section{Preliminary model diagnostics}

Caution is warranted when comparing AUC values among models from different regions and/or with different resolutions, because it can be influenced by the ratio between presence and background points (Yackulic et al. 2013). By default, Maxent uses 10000 background points, but because the total number of cells differs strongly among regions and within regions when different spatial resolutions are used, a fixed number of background points may not be adequate. We therefore calculated additional diagnostics to ensure that the models are showing their best performance and that results are comparable.

First, to determine the optimal number of background points for both spatial resolutions, we tested model performance under varying ratios of background cells to total cells, instead of using fixed cell numbers. For the coarse resolution, ratios between 10 and $50 \%$ were tested, and for the fine resolution, ratios between 0.5 and $5.0 \%$. This test showed that AUC values increased with increasing number of background points but reached a saturation point at, $40 \%$ for the coarse resolution and at , $2 \%$ for the fine-resolution analysis (Fig. S5). We used these fractions of background points for all simulations.

Second, we tested the effects of different time periods of the predictor variables and the sample size of fire events on model performance, because neither the number of fires nor the number of years for which fire data were available were consistent among regions. We achieved this with two analyses. (1) We subsampled shorter periods (i.e. temporal extents, e.g. the years 2000-04 or 2005-09) in each dataset and evaluated model performance. This analysis showed that the performance of the models for Turkey and for Switzerland was stable, irrespective of the sampled period. The models for Austria and Spain showed slight performance differences among different groups of years, but all groups were sufficiently close to the performance of the full model (Fig. S6). (2) We randomly subsampled 30,50 and $70 \%$ of the datasets and tested how the models performed with these rarefied datasets. The effect of sample size was even lower than that of different time periods. The largest differences were observed in Austria, where AUC values increased with increasing sample size (Fig. S7). In general, however, neither the temporal extent nor the sample size had a large effect on model performance, indicating that AUC values from the different regions are comparable.

\section{Importance of predictors and spatial resolution for fire occurrence}

To evaluate the importance of spatial resolution for predictions of fire occurrence, we fitted regional, cross-regional and sub-regional models at both coarse and fine spatial resolution. Regional models were fitted for Switzerland, Austria, Spain, and Turkey. For the cross-regional model, we combined the data from these regions and created a joint model based on the entire dataset. Finally, sub-regional models were calculated for the cantons of Ticino, Graubü nden and Valais in Switzerland, where the most detailed data of the present study were available.

To assess the importance of the environmental variables, we used the relative contribution of each variable as provided by Maxent. We focused on categories of variables instead of individual variables (Table 2). Because using highly correlated variables can lead to misinterpretations of the results, we performed a correlation analysis and removed highly correlated variables in a first step. To achieve this, the BIOCLIM variables were evaluated using a cross-correlation matrix. If two or more variables had a correlation (Pearson's $r$ ) higher than 0.7, their independent jack-knife test gain was checked and the variable with the lower test gain was removed. This process was repeated until no highly correlated variables remained. If the test gain of two correlated variables did not differ significantly, we favoured annual over seasonal variables (e.g. we kept annual mean temperature instead of the mean temperature of the warmest quarter; cf. discussion by Parisien and Moritz 2009). In a second step, we compared the model's AUC with and without each variable and omitted those variables that did not improve the model's AUC. To analyse model performances, we used AUC (see below for more information). We classified models as successful if their AUC \$ 0.7.

\section{Model transferability}

We systematically applied the models that were developed for one region to all other regions (for details, see below). On the one hand, the four regional models were transferred to each other, and on the other hand, the cross-regional model was applied to the four regions. All model transfers were performed at both coarse and fine spatial resolution.

For model evaluation, we used a range of diagnostics. First, we used AUC values and lowered the threshold for 'success' to 0.6 , because transferring models is a greater challenge than model calibration (Parisien and Moritz 2009). However, AUC is a single metric and may not necessarily capture spatial differences in performance. Therefore, as a second metric, we performed a correlation analysis between the prediction maps of the transferred models and the prediction maps of the original models to quantify the overlap. Because this is a standard correlation analysis and different threshold values for $\mathrm{R}^{2}$ have been used (Parisien and Moritz 2009; Parisien et al. 2012), we assumed that a model produces a successful prediction map if $\mathrm{R}^{2}$ is larger than 0.75 (i.e. the model explains at least $75 \%$ of the variation in the data). Third, we calculated the predicted ‘suitable' (i.e. fire-prone) area because a high correlation does not imply that the level (intercept) of the datasets is comparable. We used a threshold of 0.5 to determine the fireprone area (i.e. any cell with an ignition probability - 0.5) qualified as being fire-prone. We assumed that a model produces a successful prediction map if change in fire-prone area is $\# 0.25$. 


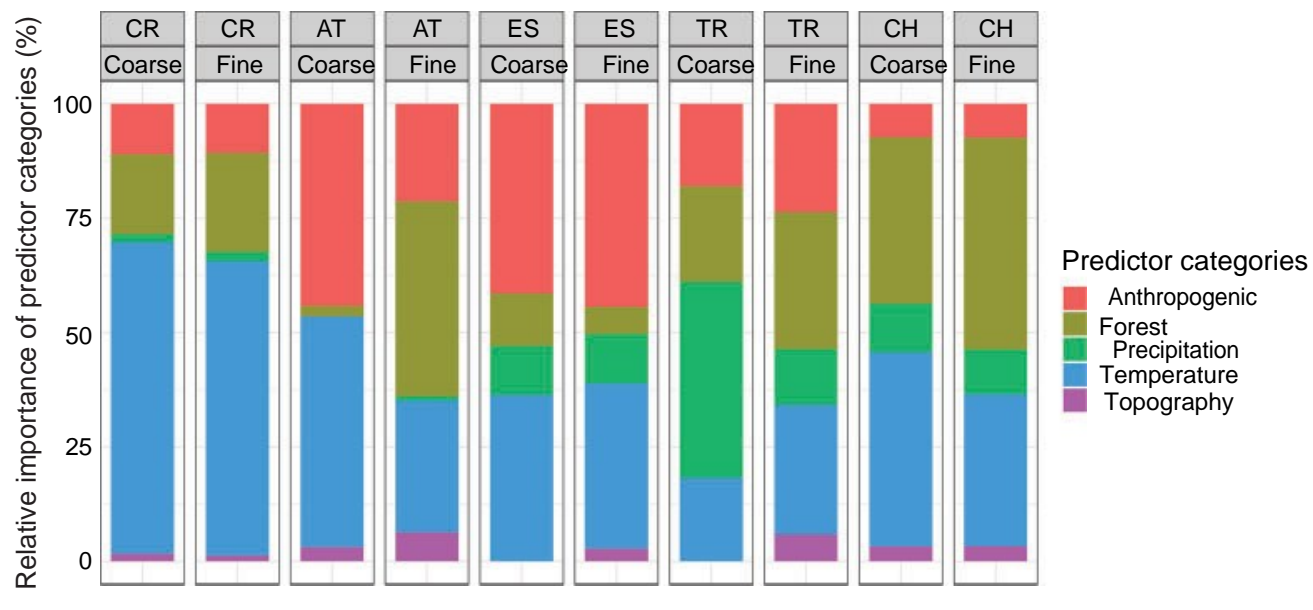

Fig. 2. Relative contribution of predictor variable categories in Maxent models at different resolutions for different regions (CR, cross-regional model; AT, Austria; ES, Spain; TR, Turkey; CH, Switzerland). For the relative contribution of individual predictor variables see Table S2 in Supplementary Material.

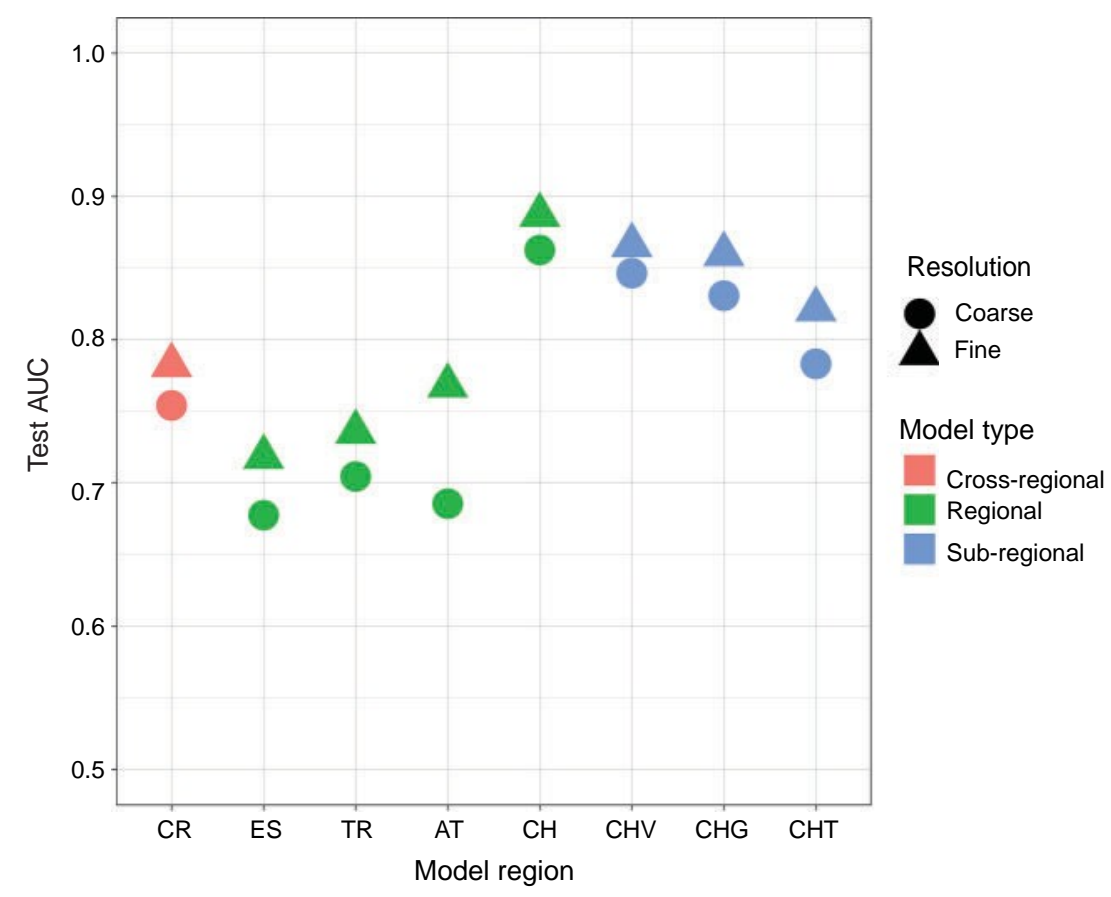

Fig. 3. Performance of cross-regional, regional and sub-regional Maxent models at coarse and fine resolution (CR, cross-regional; ES, Spain; TR, Turkey; AT, Austria; CH, Switzerland; CHV, Valais; CHG, Graubünden; CHT, Ticino).

\section{Results}

\section{Importance of predictors and spatial resolution for fire} occurrence

The comparison of the importance of the predictor variables showed that the cross-regional model had a higher contribution of climatic variables (mean $1 / 68 \%$, averaged over coarse and fine resolution models) than the regional models (mean $1 / 449 \%$; Fig. 2). Although seasonal climatic variables such as mean temperature of the wettest and driest quarters were the most important climatic variables in the cross-regional model, annual climatic variables (e.g. annual mean temperature) were the most important in the regional models (Table S2). In general, temperature variables were the main climatic contributors in all models except in the coarse resolution Turkey model, where the relative contribution of precipitation (42\%) was higher compared with temperature variables (18\%) (Fig. 2). The largest anthropogenic contribution was observed in Spain (mean1/443\%).

According to the AUC values, most models had a successful performance (AUC _ 0.7; Fig. 3). There were 6/8 successful 


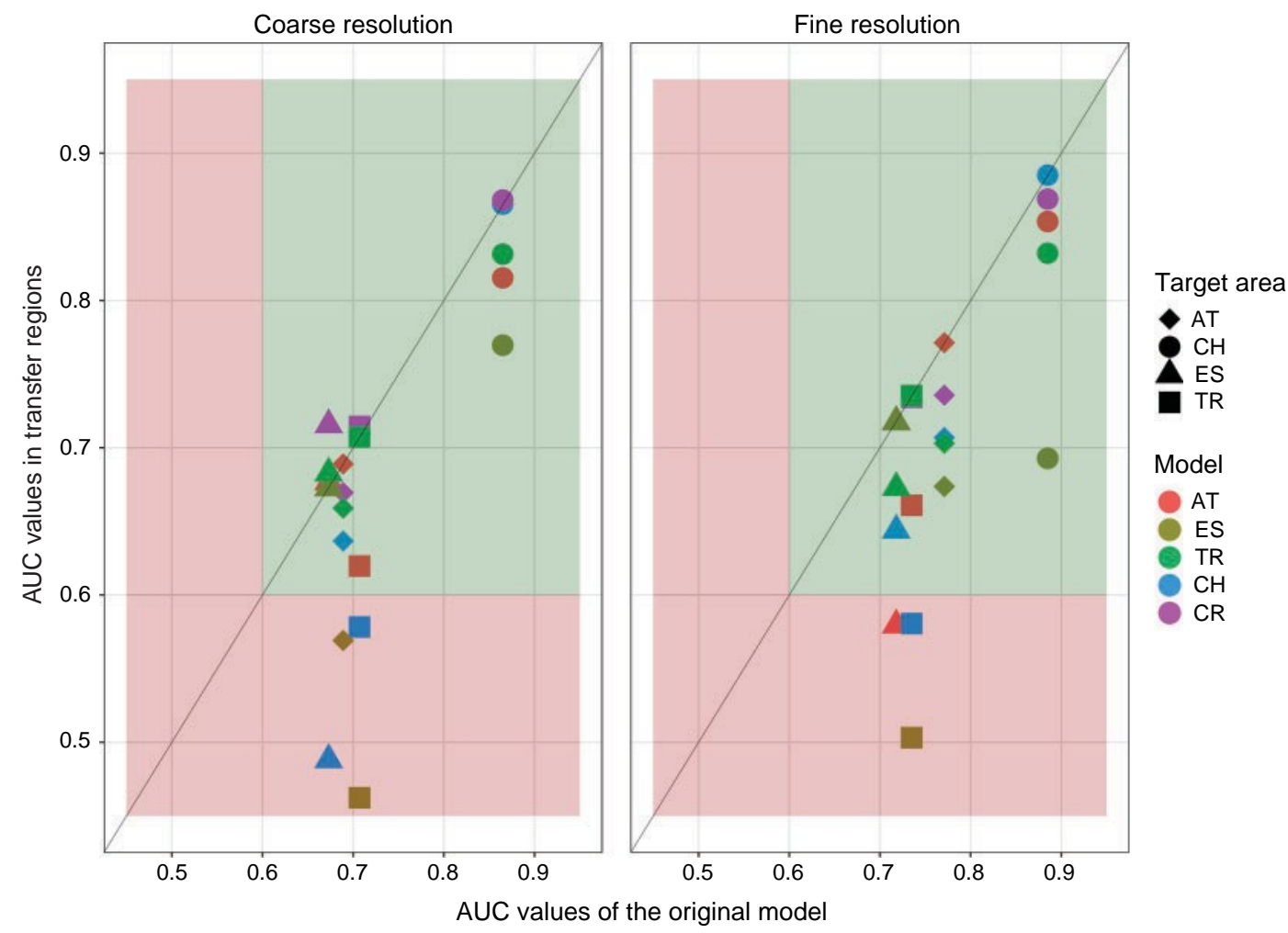

Fig. 4. Transferability results. The dots on the black line have the same performance in the original models and the transferred area (original models are also included in the graphs). Background colours indicate model performance thresholds: red, poor performance; green, good performance. CR, cross-regional model; AT, Austria; ES, Spain; TR, Turkey; CH, Switzerland.

regional models at coarse resolution and $8 / 8$ at fine resolution. Of all models, Switzerland had the best AUC performance at both resolutions and Spain had the lowest (Fig. 3). At both resolutions, the cross-regional models showed a relatively good performance (i.e. in between the best-performing Switzerland and the other regional models; Fig. 3). The three sub-regional models in Switzerland showed good performances that were, however, lower than that of the full Switzerland model. Note that the sub-regional Switzerland models are, of course, not independent from the Switzerland model, so their similar performance is not surprising. Therefore, we do not emphasise these models in the remainder of the results.

Spatial resolution played an important role for model performance. The fine resolution models performed consistently better than their coarse resolution equivalents (Fig. 3). Improvements in AUC ranged from 0.020 (Switzerland) to 0.082 (Austria). When comparing the relative contribution of the different categories of predictor variables between spatial resolutions within a region, they remained similar for the crossregional, Switzerland and Spain models (Fig. 2). However, some differences were notable in Austria and Turkey. In Austria, forest variables were more important at the fine (42.5\%) than at the coarse resolution (2.3\%), and anthropogenic variables were less important. This was mostly because of tree cover density, whose contribution was much larger at the fine resolution (Table S2). In addition, in the coarse resolution Austria model, - $90 \%$ of the contribution came from merely two variables (i.e. annual mean temperature and road network), whereas at the fine resolution, the same percentage was achieved using four variables (annual mean temperature, road network, tree cover density and aspect; Table S2). In Turkey, the difference was mostly a result of changes in the importance of climatic variables. Precipitation variables contributed to the model more at the coarse (42.8\%) than at the fine resolution (12.2\%). Similar to Austria, forest variables also had a higher contribution at the fine (30\%) than at the coarse resolution (21\%) in Turkey. Individual variables that were important at one resolution typically appeared in the other resolution as well (Table S2), but in a few cases different but highly correlated variables appeared in both resolutions.

\section{Model transferability}

Most model transfers were successful when assessed by AUC (Fig. 4). At the coarse resolution, 12 of the 16 transfers (four regional models transferred to the three other regions, plus the cross-regional model transferred to the four regions) were successful, whereas at the fine resolution, 13 of the 16 transfers were successful (AUC \$ 0.6). In all regions, the cross-regional model was successful at both resolutions when assessed for each region individually. The AUC values of model transfers were strongly influenced by the region to which the model was transferred. For instance, all models that were transferred to Switzerland showed very high AUC values, similar to the Switzerland model itself, whereas the models transferred to Turkey exhibited much lower performance and considerably more inter-model divergence (Fig. 4). 
Table 3. Coarse-resolution model transferability results

All regional models and the cross-regional model were transferred to all areas. For all metrics we used in model evaluation (Area Under the Curve (AUC), correlation and Dfire-prone area), the values above (AUC, correlation) or below (Dfire-prone area) the threshold we defined as the minimum requirement for success are marked in bold. Asterisks indicate models that were successful in all evaluation metrics. DFire-prone area is the difference between fire prone area of the original model and fire prone area of the model in transferred region. Values inside the parenthesis represent relative change in Dfire-prone area

\begin{tabular}{|c|c|c|c|c|c|}
\hline Model & Transfer area & AUC & Correlation & Fire-prone area (\%) & DFire-prone area \\
\hline Austria & & 0.689 & & 0.44 & \\
\hline Switzerland* & Austria & 0.637 & 0.82 & 0.55 & 0.11 (25\%) \\
\hline Spain & Austria & 0.569 & 0.50 & 0.00 & $-0.44(-100 \%)$ \\
\hline Turkey & Austria & 0.659 & 0.57 & 0.00 & $-0.44(-100 \%)$ \\
\hline Cross-regional* & Austria & 0.670 & 0.85 & 0.22 & $20.22(-50 \%)$ \\
\hline Switzerland & & 0.865 & & 0.15 & \\
\hline Austria* & Switzerland & 0.815 & 0.79 & 0.28 & $0.13(87 \%)$ \\
\hline Spain & Switzerland & 0.770 & 0.33 & 0.00 & $20.15(-100 \%)$ \\
\hline Turkey & Switzerland & 0.831 & 0.62 & 0.00 & $20.15(-100 \%)$ \\
\hline Cross-regional* & Switzerland & 0.868 & 0.90 & 0.15 & $\mathbf{0 . 0 0}(0 \%)$ \\
\hline Spain & & 0.673 & & 0.45 & \\
\hline Austria & Spain & 0.677 & 0.50 & 0.25 & $20.21(-44 \%)$ \\
\hline Switzerland & Spain & 0.488 & 0.28 & 0.55 & $\mathbf{0 . 1 0}(22 \%)$ \\
\hline Turkey & Spain & 0.683 & 0.76 & 0.00 & $-0.45(-100 \%)$ \\
\hline Cross-regional & Spain & 0.715 & 0.88 & 0.86 & $0.41(91 \%)$ \\
\hline Turkey & & 0.707 & & 0.50 & \\
\hline Austria & Turkey & 0.620 & 0.33 & 0.89 & $0.39(78 \%)$ \\
\hline Switzerland & Turkey & 0.578 & 0.24 & 0.00 & $-0.50(-100 \%)$ \\
\hline Spain & Turkey & 0.462 & 0.08 & 0.06 & $-0.44(-88 \%)$ \\
\hline Cross-regional* & Turkey & 0.714 & 0.95 & 0.35 & $20.15(-30 \%)$ \\
\hline
\end{tabular}

In addition to assessing model performance based on AUC, the spatial patterns of the prediction maps were compared between the transferred models and the original models using a correlation analysis in terms of the predicted fire-prone area (for the predicted fire occurrence maps, see Figs. S8-15). The prediction maps of the successful models (judged by AUC) most often showed a spatial pattern similar to those of the original models, with some exceptions. For instance, the coarse resolution Turkey model featured prediction maps that were highly different from the original model outcomes when it was applied to the other regions, despite having 'successful' AUC values (Fig. S14). Overall, however, of the 12 successful models at coarse resolution (judged by AUC), seven maps were highly correlated ( $r$ \$ 0.7) with the original prediction map, and at fine resolution, nine out of 13 successful models produced highly correlated maps (Tables 3, 4).

Finally, the comparison of the predicted fire-prone area across models showed that, at the coarse resolution, five out of the seven successful models featured a similar area (Dfire-prone area \#0.25). For the fine resolution, six out of nine successful models showed similar values of the predicted fire-prone area (cf. Table 4). Overall, five and six models at the coarse and fine resolution, respectively, yielded (1) a high AUC, (2) highly correlated prediction maps and (3) similar predicted fire-prone areas. Notably, the cross-regional model was among this set in three cases (Switzerland, Turkey and Austria) for both resolutions (Tables 3, 4). Only in Spain did the cross-regional model predict a much larger fire-prone area than the original model outcome at both resolutions; the other metrics still indicated a high model performance.

\section{Discussion}

\section{Importance of predictors and spatial resolution for fire occurrence modelling}

Our results suggest that the importance of predictor variables differs between the regional and the cross-regional models. The most striking difference is the decisively higher contribution of climatic predictors in the cross-regional model in comparison with regional models. This indicates that at the regional level, anthropogenic factors and land cover and/or land use are important for differentiating the occurrence of wildfires at this spatial scale, but at the cross-regional (continental) scale the climatic factors gain in importance. Our results are consistent with findings from previous studies showing that the impact of climate is dominant at the macro scale (Pearson et al. 2002), and that the influence of climate-related factors can be overridden by other factors at smaller scales (Wiens 1989).

Our analyses further showed that the importance of factors varies among regions, but sometimes also between different resolutions within a region. Between Spain and Switzerland, where the results were only slightly influenced by the resolution, the significance of anthropogenic factors differed distinctly. The strong influence of anthropogenic factors that we found for Spain is consistent with the findings of Padilla and Vega-Garc' 1 a (2011), in which road density was the most important explanatory variable for a large part of the Valencia region. The low importance of anthropogenic factors in Switzerland, however, does not agree with the results of Zumbrunnen et al. (2012) showing a pronounced influence of humans on wildfires. That study, however, considered additional anthropogenic factors 
Table 4. Fine-resolution model transferability results

All regional models and the cross-regional model were transferred to all areas. For all metrics we used in model evaluation (Area Under the Curve (AUC), correlation and Dfire-prone area), the values above (AUC, Correlation) or below (DFire-prone area) the threshold we defined as the minimum requirement for success are marked in bold. Asterisks indicate models that were successful in all evaluation metrics. DFire-prone area is the difference between fire prone area of the original model and fire prone area of the model in transferred region. Values inside the parenthesis represent relative change in Dfire-prone area

\begin{tabular}{|c|c|c|c|c|c|}
\hline Model & Transfer area & AUC & Correlation & Fire-prone area (\%) & DFire-prone area \\
\hline Austria & & 0.771 & & 0.25 & \\
\hline Switzerland* & Austria & 0.707 & 0.88 & 0.38 & $\mathbf{0 . 1 4}(52 \%)$ \\
\hline Spain & Austria & 0.674 & 0.67 & 0.00 & $20.25(-100 \%)$ \\
\hline Turkey & Austria & 0.703 & 0.83 & 0.67 & $0.42(168 \%)$ \\
\hline Cross-regional* & Austria & 0.736 & 0.85 & 0.16 & $20.08(-36 \%)$ \\
\hline Switzerland & & 0.885 & & 0.12 & \\
\hline Austria* & Switzerland & 0.854 & 0.84 & 0.12 & $\mathbf{0 . 0 0}(0 \%)$ \\
\hline Spain & Switzerland & 0.693 & 0.21 & 0.02 & $20.10(-83 \%)$ \\
\hline Turkey* & Switzerland & 0.832 & 0.78 & 0.22 & $0.11(83 \%)$ \\
\hline Cross-regional* & Switzerland & 0.869 & 0.90 & 0.12 & $\mathbf{0 . 0 0}(0 \%)$ \\
\hline Spain & & 0.718 & & 0.31 & \\
\hline Austria & Spain & 0.580 & 0.40 & 0.38 & $\mathbf{0 . 0 7}(23 \%)$ \\
\hline Switzerland & Spain & 0.644 & 0.49 & 0.00 & $-0.31(-100 \%)$ \\
\hline Turkey & Spain & 0.673 & 0.71 & 0.00 & $-0.31(-100 \%)$ \\
\hline Cross-regional & Spain & 0.736 & 0.86 & 0.71 & $0.39(129 \%)$ \\
\hline Turkey & & 0.735 & & 0.40 & \\
\hline Austria & Turkey & 0.661 & 0.58 & 0.32 & $20.08(-20 \%)$ \\
\hline Switzerland & Turkey & 0.581 & 0.19 & 0.00 & $-0.40(-100 \%)$ \\
\hline Spain & Turkey & 0.503 & 0.24 & 0.00 & $-0.40(-100 \%)$ \\
\hline Cross-regional* & Turkey & 0.734 & 0.94 & 0.19 & $20.21(-53 \%)$ \\
\hline
\end{tabular}

such as population density, which we did not include owing to the lack of high-resolution population data across all regions. Thus, the choice of factors used in a modelling study can considerably influence the results and their interpretation, rendering comparisons between studies difficult. An assessment of the relative importance of factors should therefore always be considered with caution. In steep mountain conditions, for instance, the road network depends on the geomorphologic constraints, making it a totally different proxy for anthropogenic influence with respect to hilly or flat regions (Conedera et al. 2015). Similarly, in mountain regions, settlements are clustered on valley floors or slope terraces. Under such conditions, the increasing distance from settlements or roads when following the altitudinal gradient may be highly correlated with the temperature, which in turn tends to decrease with altitude, making the analysis of potential fire drivers based on such proxies quite speculative. However, strong regional differences in the wildland-urban interface in Switzerland could also be responsible for not finding a common pattern (Conedera et al. 2015). Finally, it is worth mentioning that Pezzatti et al. (2013) found clear fire regime shifts in the Ticino and Valais regions from 1904 to 2008 that were traceable to land use or legal changes, indicating increasing anthropogenic influences in those regions.

In contrast to Spain and Switzerland, the importance of variables differed between spatial resolutions in Austria and Turkey. In Austria, the increasing importance of forest variables at fine resolution may be connected with the prevailing smallscale mosaic of irregularly shaped forest plots. Because forest fires are important in that area (Arndt et al. 2013), the distribution of forest area may be captured sufficiently at the fine resolution only, explaining the high importance of this variable. The insufficient representation of forest area at low resolution may also be a reason why the performance of that model was much lower compared with the fine scale model. In Turkey, our results showed the dominance of nonanthropogenic factors in the region, which is in accordance with the findings of Bekar (2016; see also Bekar and Tavsanoğlu 2017). In that study, temperature and precipitation were found to be the most important factors for the distribution of fire occurrence. Bekar (2016) further found that elevation strongly influences the importance of temperature and precipitation (i.e. temperature was important for mid-elevations), whereas precipitation was important at very low and high elevations. Our results showed that although temperature and forest variables were the dominant variables at the fine resolution, precipitation was more important at the coarse resolution in Turkey. These results highlight that spatial resolution is important for overall model performance and sometimes also for the relative contribution of factors.

Fire occurrence is influenced by a variety of factors. Although important climatic and topographic factors can be represented relatively well in spatial models, accounting for anthropogenic influences is more challenging because it requires the identification, quantification and mapping of behavioural factors (Vilar et al. 2016b), which may differ further between regions. In the present study, the two best performing models (cross-regional and Switzerland) had a low contribution from anthropogenic variables, and the worst performing models (Spain and coarse resolution Austria) had a high contribution. 
A possible reason for the lower performance of the latter models may lie with the high importance of some other anthropogenic variables that are missing in our dataset (cf. Parisien and Moritz 2009). For instance, several studies showed the importance of the extent and nature of the wildland-urban interface for fire occurrence in Spain (Vilar et al. 2010; Martínez-Fernández et al. 2013; Vilar et al. 2016a). Thus, to better represent human influences on fire occurrence, variables such as the population density in the wildland-urban interface may need to be included in further studies (Martínez-Fernández et al. 2013).

Our results clearly demonstrate that spatial resolution is an important factor affecting model performance. To our knowledge, only Cardille et al. (2001) investigated the effect of spatial resolution on the performance of fire occurrence models, surprisingly finding decreasing model performance with increasing resolution (from $10 \mathrm{~km}$ to $5 \mathrm{~km}$ ), which is in contrast to our results. However, studies that analysed the effect of resolution for other entities in SDMs repeatedly showed increased performance with increasing resolution (Guisan et al. 2007a; Guisan et al. 2007b; Gottschalk et al. 2011; Ross et al. 2015). Clearly, further modelling studies evaluating the effect of different spatial resolutions on fire occurrence predictions are needed, and we advocate using a range of different resolutions to get a clearer picture.

There is no consensus regarding the effect of spatial resolution on the importance of predictors. Some studies show that spatial resolution clearly influences the relative importance of the variables (Hanberry 2013; Suárez-Seoane et al. 2014), but others show no significant effects (Cardille et al. 2001; Pradervand et al. 2014). These ambiguous results may be a result of variations in the absolute or relative differences of the resolutions compared in the respective studies. For instance, an increase in resolution from $10 \mathrm{~km}$ to $5 \mathrm{~km}$ does not necessarily have to better capture the relevant factors, but could be possible with an increase from $1 \mathrm{~km}$ to $100 \mathrm{~m}$. In the present study the differences in resolution were consistent across regions, but we still observed regional differences. While the relative importance was similar in Switzerland and Spain, distinct differences were observed in Austria and Turkey, where forest variables were considerably more important at fine resolution. In accordance with the study by Guisan et al. (2007a), this result indicates that the effect of spatial resolution on contributing factors can vary regionally. In homogenous landscapes, a coarse resolution may be sufficient, but in complex, environmentally and topographically heterogeneous landscapes, a fine resolution may be required to capture the essential mechanism. Although further research that systematically tests the effect of grain size on model performance is needed, it is worth mentioning that the aim should not be to identify the 'gold standard' for spatial resolution in fire occurrence models, but to identify the most appropriate resolution for the relevant parameters considered in the study object.

\section{Model transferability}

We used three metrics to evaluate model transfers because using only AUC could lead to misleading results. For instance, the AUC of the models was partly determined by the region to which the model was transferred. Particularly in Switzerland, all models had a successful AUC performance, most likely because non-fire-prone areas (absences) were much more common owing to the complex topography of the region, consisting of many high-elevation, high-precipitation areas. Most of the models were able to predict these absences accurately, resulting in high AUC even though presences may not be predicted well. The Austria model was the only one that also accurately predicted presences for Switzerland, as indicated by the other metrics. This shows that despite high AUC values, models may produce different prediction maps when they are transferred, thus it is important to apply multi-criteria assessments.

Spatial transferability is a desirable feature of models, because it underpins their general applicability (Randin et al. 2006). In the present study, all of the spatial transfers of the regional models were not successful (when assessed by multiple criteria), with some exceptions. For instance, a successful regional model transfer was possible between Switzerland and Austria. These two Alpine regions had overlapping explanatory variables in their final models and therefore the transfer was successful. Successful transfer was not possible between the Mediterranean regions, because although they are climatically similar, they differ considerably in the non-climatic factors. These results show that model transfer between regions is only possible if there is a certain overlap among the environmental conditions between the origin and target area of the model.

In contrast to regional model transfers, the cross-regional model performed successfully in nearly all regions. This is not surprising considering that the data from all regions were used to fit it. However, this alone does not necessarily guarantee successful performance at the level of the individual regions. If the drivers of fire occurrence were considerably different between regions, a cross-regional model would unlikely be able to predict these differences. In our case, the drivers of fire occurrence in Spain differed notably from those in the other regions, with a much higher contribution of anthropogenic factors. This may be the reason why Spain was the only region in which the cross-regional model failed in one assessment criterion. When attempting to simulate future effects of climate change on fire occurrence, the cross-regional model may make more reasonable predictions in the former three regions than in the regional models, because it was calibrated to a wider climatic range and has a higher contribution of climatic predictor variables. However, owing to the large importance of anthropogenic factors in Spain, future predictions by the crossregional model are uncertain - more research on the ability to predict future fire occurrences by regional and cross- regional models is needed.

\section{Conclusion}

We found that the predictions of the cross-regional model when transferred to the different regions are more robust than those of the transferred regional models. The performance of transferred regional models can be poor even between climatically similar regions because anthropogenic factors often differ substantially. Cross-regional models may be better suited to predict the future effects of climate change on fire occurrence, owing to their better representation of climatic differences. However, further research is required.

We demonstrated that spatial resolution influences performance and sometimes also the relative importance of the predictor variables of fire occurrence models. The spatial 
distribution of factors influencing wildfires can differ considerably between regions, and some landscape patterns may only be sufficiently well represented at a specific resolution. This indicates that when modelling fire occurrence, attention should be given to finding an appropriate spatial resolution, and that we generally need a better understanding of the effects of scale and resolution in fire occurrence models.

\section{Conflicts of interest}

The authors declare no conflicts of interest.

\section{Acknowledgements}

We thank Timothy Thrippleton for his help with programming in R. This project is partly funded by a Swiss Government Excellence Scholarship. JGP thanks the PROMETEO/2016/021 project.

\section{References}

Arndt N, Vacik H, Koch V, Arpaci A, Gossow H (2013) Modeling humancaused forest fire ignition for assessing forest fire danger in Austria. IForest 6, 315-325. doi:10.3832/IFOR0936-006

Arpaci A, Malowerschnig B, Sass O, Vacik H (2014) Using multi variate data mining techniques for estimating fire susceptibility of Tyrolean forests. Applied Geography 53, 258-270. doi:10.1016/J.APGEOG. 2014.05.015

Bekar İ (2016) Akdeniz ekosistemlerinde günümüz yangin rejimlerinin sekillenmesinde doğal ve antropojen faktörlerin rolü. Translated title:

The role of anthropogenic and natural factors in shaping recent fire regimes in Mediterranean ecosystems. M.Sc. Thesis, Hacettepe University, Ankara, Turkey. [In Turkish] Availableat http://www.openaccess. hacettepe.edu.tr:8080/xmlui/handle/11655/4914 [Verified March 2020]

Bekar İ, Tavsanoğlu Ç (2017) Modelling the drivers of natural fire activity: the bias created by cropland fires. International Journal of Wildland Fire 26, 845-851. doi:10.1071/WF16183

Bond WJ, Woodward FI, Midgley GF (2005) The global distribution of ecosystems in a world without fire. New Phytologist 165, 525-538. doi:10.1111/J.1469-8137.2004.01252.X

Camp PE, Krawchuk MA (2017) Spatially varying constraints of humancaused fire occurrence in British Columbia, Canada. International Journal of Wildland Fire 26, 219-229. doi:10.1071/WF16108

Cardille JA, Ventura SJ, Turner MG (2001) Environmental and social factors influencing wildfires in the Upper Midwest, United States. Ecological Applications 11, 111-127. doi:10.1890/10510761(2001)011[0111:EASFIW]2.0.CO;2

Chergui B, Fahd S, Santos X, Pausas JG (2017) Socioeconomic factors drive fire-regime variability in the Mediterranean Basin. Ecosystems 21, 1-10.

Conedera M, Tonini M, Oleggini L, Vega Orozco C, Leuenberger M, Pezzatti GB (2015) Geospatial approach for defining the wildlandurban interface in the alpine environment. Computers, Environment and Urban Systems 52, 10-20. doi:10.1016/J.COMPENVURBSYS.2015. 02.003

Conedera M, Krebs P, Valese E, Cocca G, Schunk C, Menzel A, Vacik H, Cane D, Japelj A, Muri B, Ricotta C, Oliveri S, Pezzatti GB (2018) Characterizing alpine pyrogeography from fire statistics. Applied Geography 98, 87-99. doi:10.1016/J.APGEOG.2018.07.011

De Angelis A, Ricotta C, Conedera M, Pezzatti GB (2015) Modelling the meteorological forest fire niche in heterogeneous pyrologic conditions. PLoS One 10, e0116875. doi:10.1371/JOURNAL.PONE.0116875

Dimitrakopoulos AP, Vlahou M, Anagnostopoulou CG, Mitsopoulos ID (2011) Impact of drought on wildland fires in Greece: implications of climatic change? Climatic Change 109, 331-347. doi:10.1007/S10584011-0026-8
Elith J, Leathwick JR (2009) Species distribution models: ecological explanation and prediction across space and time. Annual Review of Ecology Evolution and Systematics 40, 677-697. doi:10.1146/ ANNUREV.ECOLSYS.110308.120159

Elith J, Graham CH, Anderson RP, Dudik M, Ferrier S, Guisan A, Hijmans RJ, Huettmann F, Leathwick JR, Lehmann A, Li J, Lohmann LG, Loiselle BA, Manion G, Moritz C, Nakamura M, Nakazawa Y, Overton JM, Peterson AT, Phillips SJ, Richardson K, Scachetti-Pereira R, Schapire RE, Soberon J, Williams S, Wisz MS, Zimmermann NE (2006) Novel methods improve prediction of species' distributions from occurrence data. Ecography 29, 129-151. doi:10.1111/J.2006.09067590.04596.X

Fick SE, Hijmans RJ (2017) WorldClim 2: new 1-km spatial resolution climate surfaces for global land areas. International Journal of Climatology 37, 4302-4315. doi:10.1002/JOC.5086

Gottschalk TK, Aue B, Hotes S, Ekschmitt K (2011) Influence of grain size on species-habitat models. Ecological Modelling 222, 3403-3412. doi:10.1016/J.ECOLMODEL.2011.07.008

Grima N (2011) Forest fire hazard mapping in Carinthia (Southern Austria). M.Sc. Thesis, University of Natural Resources and Applied Life Sciences (BOKU), Vienna. Available at http://bit.ly/2EwTETb [Verified March 2020]

Guisan A, Zimmermann NE (2000) Predictive habitat distribution models in ecology. Ecological Modelling 135, 147-186. doi:10.1016/S03043800(00)00354-9

Guisan A, Graham CH, Elith J, Huettmann F, Dudik M, Ferrier S, Hijmans R, Lehmann A, Li J, Lohmann LG, Loiselle B, Manion G, Moritz C, Nakamura M, Nakazawa Y, Overton JMC, Peterson AT, Phillips SJ, Richardson K, Scachetti-Pereira R, Schapire RE, Williams SE, Wisz MS, Zimmermann NE (2007a) Sensitivity of predictive species distribution models to change in grain size. Diversity \& Distributions 13, 332340. doi:10.1111/J.1472-4642.2007.00342.X

Guisan AA, Zimmermann NE, Elith J, Graham CH, Phillips S, Guisan A, Zimmermann NE, Elith J, Graham CH, Phillips S, Peterson AT (2007b) What matters for predicting the occurrences of trees: techniques, data, or species’ characteristics? Ecological Monographs 77, 615-630. doi:10. 1890/06-1060.1

Haklay M, Weber P (2008) OpenStreetMap: user-generated street maps. Pervasive Computing 7, 12-18. doi:10.1109/MPRV.2008.80

Hanberry BB (2013) Finer grain size increases effects of error and changes influence of environmental predictors on species distribution models. Ecological Informatics 15, 8-13. doi:10.1016/J.ECOINF.2013.02.003

Hijmans RJ, Phillips S, Leathwick J, Elith J (2017) ‘dismo: species distribution modeling.' R package version 1.1-4. Available at https://cran. rproject.org/web/packages/dismo/index.html [Verified March 2020]

Jolly WM, Cochrane MA, Freeborn PH, Holden ZA, Brown TJ, Williamson GJ, Bowman DMJS (2015) Climate-induced variations in global wildfire danger from 1979 to 2013. Nature Communications 6, 7537. doi:10. 1038/NCOMMS8537

Koutsias N, Martínez-Fernández J, Chuvieco E, Allgöwer B (2005) Modelling wildland fire occurrence in southern Europe by geographically weighted regression approach. In 'Proceedings of the 5th International Workshop on Remote Sensing and GIS Applications to Forest Fire Management: Fire Effects Assessment', 16-18 June 2005, Zaragoza, Spain. (Eds J De La Riva, F Pérez-Cabello, E Chuvieco) pp. 57-60. (Universidad de Zaragoza: Zaragoza, Spain)

Koutsias N, Martínez-Fernández J, Allgöwer B (2010) Do factors causing wildfires vary in space? Evidence from geographically weighted regression. GIScience \& Remote Sensing 47, 221-240. doi:10.2747/15481603.47.2.221

Martínez-Fernández J, Chuvieco E, Koutsias N (2013) Modelling longterm fire occurrence factors in Spain by accounting for local variations with geographically weighted regression. Natural Hazards and Earth System Sciences 13, 311-327. doi:10.5194/NHESS-13-311-2013 
Moreira F, Rego FC, Ferreira PG (2001) Temporal (1958-1995) pattern of change in a cultural landscape of northwestern Portugal: implications for fire occurrence. Landscape Ecology 16, 557-567. doi:10.1023/ A:1013130528470

Müller M, Vacik H, Valese E (2015) Anomalies of the Austrian forest fire regime in comparison with other alpine countries: a research note. Forests 6, 903-913. doi:10.3390/F6040903

Padilla M, Vega-Garc'ia C (2011) On the comparative importance of fire danger rating indices and their integration with spatial and temporal variables for predicting daily human-caused fire occurrences in Spain. International Journal of Wildland Fire 20, 46-58. doi:10.1071/WF09139

Parisien MA, Moritz MA (2009) Environmental controls on the distribution of wildfire at multiple spatial scales. Ecological Monographs 79, 127 154. doi:10.1890/07-1289.1

Parisien MA, Snetsinger S, Greenberg JA, Nelson CR, Schoennagel T, Dobrowski SZ, Moritz MA (2012) Spatial variability in wildfire probability across the western United States. International Journal of Wildland Fire 21, 313-327. doi:10.1071/WF11044

Pausas JG (2004) Changes in fire and climate in the eastern Iberian Peninsula (Mediterranean Basin). Climatic Change 63, 337-350. doi:10.1023/B:CLIM.0000018508.94901.9C

Pausas JG, Fernández-Muñoz S (2012) Fire regime changes in the western Mediterranean Basin: from fuel-limited to drought-driven fire regime. Climatic Change 110, 215-226. doi:10.1007/S10584-011-0060-6

Pausas JG, Keeley JE (2009) A burning story: the role of fire in the history of life. Bioscience 59, 593-601. doi:10.1525/BIO.2009.59.7.10

Pausas JG, Keeley JE (2014) Abrupt climate-independent fire regime changes. Ecosystems 17, 1109-1120. doi:10.1007/S10021-014-9773-5

Pausas JG, Keeley JE (2019) Wildfires as an ecosystem service. Frontiers in Ecology and the Environment 17, 289-295. doi:10.1002/FEE.2044

Pearson RG, Dawson TP, Berry PM, Harrison PA (2002) SPECIES: a spatial evaluation of climate impact on the envelope of species. Ecological Modelling 154, 289-300. doi:10.1016/S0304-3800(02)00056-X

Pezzatti GB, Zumbrunnen T, Bürgi M, Ambrosetti P, Conedera M (2013) Fire regime shifts as a consequence of fire policy and socio-economic development: an analysis based on the change point approach. Forest Policy and Economics 29, 7-18. doi:10.1016/J.FORPOL.2011.07.002

Phillips SJ, Anderson RP, Schapire RE (2006) Maximum entropy modeling of species geographic distributions. Ecological Modelling 190, 231-259. doi:10.1016/J.ECOLMODEL.2005.03.026

Pradervand J-N, Dubuis A, Pellissier L, Guisan A, Randin C (2014) Very high resolution environmental predictors in species distribution models: moving beyond topography? Progress in Physical Geography 38, 7996. doi:10.1177/0309133313512667

R Core Team (2018) 'R: A Language and Environment for Statistical Computing.' (R Foundation for Statistical Computing: Vienna) Available at https://www.R-project.org [Verified March 2020]

Randin CF, Dirnbö ck T, Dullinger S, Zimmermann NE, Zappa M, Guisan A (2006) Are niche-based species distribution models transferable in space? Journal of Biogeography 33, 1689-1703. doi:10.1111/J.13652699.2006.01466.X

Renard Q, Plissier R, Ramesh BR, Kodandapani N (2012) Environmental susceptibility model for predicting forest fire occurrence in the western ghats of India. International Journal of Wildland Fire 21, 368-379. doi:10.1071/WF10109

Ross LK, Ross RE, Stewart HA, Howell KL (2015) The influence of data resolution on predicted distribution and estimates of extent of current protection of three 'listed' deep-sea habitats. PLoS One 10, e0140061. doi:10.1371/JOURNAL.PONE.0140061

Schelhaas M-J, Nabuurs G-J, Schuck A (2003) Natural disturbances in the European forests in the 19th and 20th Centuries. Global Change Biology 9, 1620-1633. doi:10.1046/J.1365-2486.2003.00684.X

Schumacher S, Bugmann H (2006) The relative importance of climatic effects, wildfires and management for future forest landscape dynamics in the Swiss Alps. Global Change Biology 12, 1435-1450. doi:10.1111/ J.1365-2486.2006.01188.X

Seidl R, Schelhaas MJ, Lexer MJ (2011) Unraveling the drivers of intensifying forest disturbance regimes in Europe. Global Change Biology 17, 2842-2852. doi:10.1111/J.1365-2486.2011.02452.X

Suárez-Seoane S, Virgós E, Terroba O, Pardavila X, Barea-Azcón JM (2014) Scaling of species distribution models across spatial resolutions and extents along a biogeographic gradient. The case of the Iberian mole Talpa occidentalis. Ecography 37, 279-292. doi:10.1111/J.1600-0587. 2013.00077.X

Turco M, Bedia J, Liberto FD, Fiorucci P, von Hardenberg J, Koutsias N, Llasat M-C, Xystrakis F, Provenzale A (2016) Decreasing fires in Mediterranean Europe. PLOS ONE 11, e0150663. doi:10.1371/ JOURNAL.PONE.0150663

Vilar L, Woolford DG, Martell DL, Martn MP (2010) A model for predicting human-caused wildfire occurrence in the region of Madrid, Spain. International Journal of Wildland Fire 19, 325-337. doi:10.1071/ WF09030

Vilar L, Camia A, San-Miguel-Ayanz J, Mart'ın MP (2016a) Modeling temporal changes in human-caused wildfires in Mediterranean Europe based on land use-land cover interfaces. Forest Ecology and Management 378, 68-78. doi:10.1016/J.FORECO.2016.07.020

Vilar L, Gómez I, Martínez-Vega J, Echavarría P, Riaño D, Martín MP (2016b) Multitemporal modelling of socio-economic wildfire drivers in central Spain between the 1980s and the 2000s: comparing generalized linear models to machine learning algorithms. PLoS One 11, e0161344. doi:10.1371/JOURNAL.PONE.0161344

Weibel P (2009) Modelling and assessing fire regimes in mountain forests of Switzerland. Ph.D. Thesis, Swiss Federal Institute of Technology, Zürich. Available at https://www.research-collection.ethz.ch/handle/ 20.500.11850/21817 [Verified March 2020]

Westerling AL, Hidalgo HL, Cayan DR, Swetnam TW (2006) Warming and earlier spring increase western U.S. forest wildfire activity. Science 313, 940-943. doi:10.1126/SCIENCE.1128834

Wiens JA (1989) Spatial scaling in ecology. Functional Ecology 3, 385397. doi:10.2307/2389612

Yackulic CB, Chandler R, Zipkin EF, Royle JA, Nichols JD, Campbell Grant EH, Veran S (2013) Presence-only modelling using MAXENT: when can we trust the inferences? Methods in Ecology and Evolution 4, 236-243. doi:10.1111/2041-210X.12004

Zumbrunnen $\mathrm{T}$ (2010) Reconstructing and analyzing the fire history in a dry continental valley (Valais) of the Swiss Alps. Ph.D. Thesis, Swiss Federal Institute of Technology, Zürich. Available at https://www. research-collection.ethz.ch/handle/20.500.11850/114055 [Verified March 2020]

Zumbrunnen T, Menéndez P, Bugmann H, Conedera M, Gimmi U, Bürgi M (2012) Human impacts on fire occurrence: a case study of hundred years of forest fires in a dry alpine valley in Switzerland. Regional Environmental Change 12, 935-949. doi:10.1007/S10113012-0307-4 